\title{
Educators' Perceptions of Performance-Based Approaches in Teaching Difference With Youth
}

\author{
Madison E. Gaudry-Routledge and Marni J. Binder
}

\begin{abstract}
Recent research into critical pedagogy supports the implementation of performance-based practices into the classroom. This qualitative research explored the pragmatic ways in which youth, ages 8-17, are taught in Canada's, specifically Ontario's, education system on topics of difference and power. Through semi-structured interviews, four elementary and high school educators described their experiences using performance-based teaching in the classroom. A thematic analysis revealed that teachers found including such practices empowered students and influenced their understanding of their own identities as well as the systemic oppression of marginalized groups.
\end{abstract}

\section{Background}

Over the past 20 years, many Western countries have experienced significant demographic shifts (Ryan, Pollock \& Antonelli, 2009; Daniel, 2016; Duffy \& Powers, 2018). The intersectionality of various identity markers is one of the many factors that have inevitably made contemporary classrooms significantly more diverse and complex (Gallagher, 2014; Duffy \& Powers, 2018). Consequently, the role of a teacher now entails certain demands that greatly exceed traditional requirements, subject matter, and teaching models (Duffy \& Powers, 2018). While the diversity of student populations continues to rapidly grow, the proportion of racially, ethnically, and linguistically diverse teachers continues to decline (Solomon \& Singer; 2011; Matias \& Mackey; 2016).

Education has a crucial role in both navigating through the challenges, while supporting and cultivating the potential of diversity (Denzin, 2018). Pedagogical frameworks must be action-oriented and directly address racism, as well as the inevitable complexities and intersections of difference within the educational system (Davis \& Harrison, 2013; Ghosh \& Galczynski, 2014; Dei, 2014a). This study explored the pragmatic ways in which individuals, particularly youth ages 8-17, are taught within the Canadian education system, specifically Ontario, on topics of racial, social, and cultural differences. Also considered are how this influences students' understanding of the construction of identity, and the systemic oppression of marginalized groups.

Research suggests that performance-based pedagogical methods have proven to be highly valuable in the area of addressing difference and influencing social change. This establishes a community that educates and empowers participants, including both students and educators, which is conducive to critical understanding and fostering a safe, equitable learning environment (Snyder-Young, 2011; Gallagher, 2014; Desai, 2017; Duffy \& Powers, 2018). This article presents a qualitative descriptive study 
on how four educators experienced incorporating performance-based teaching practices into their classrooms. By cultivating an open space, students were free to express themselves and pose questions that are often pushed to the periphery in classroom settings. The benefits and challenges of incorporating critical performance-based methods into their teaching demonstrated how such practices can help to facilitate social change.

\section{Conceptual Framework}

Guided by a critical pedagogical approach (Freire, 1970; Giroux, 1997; hooks, 1994; 2003) and performance-based pedagogy, this study drew on the work of Augusto Boal (1979). Exploring how teachers address topics of difference and marginalization with their students through performance-based methods, raises questions about the significance of these, often unexamined, issues. (Solomon \& Singer, 2011). Performance-based pedagogy has long been associated with critical pedagogy and anti-oppressive education as it embodies reflective practices that hold the potential to subvert traditional epistemological frameworks of teachers and the importance of teaching through theatre (Duffy \& Powers, 2018).

\section{Student Learning Through Performative Critical Pedagogy}

Various studies have noted the feasibility and success of integrating performance-based methods into elementary, middle school, and high school curriculums, particularly when addressing issues of power imbalance and oppression (Gallagher; 2014; Desai, 2017; Denzin, 2018; Duffy \& Powers, 2018). Cahnmann-Taylor and Souto-Manning (2010) suggested that drama and performance-based art are highly valuable methods in the process of developing critical, anti-oppressive learning environments. They integrated performance-based teaching with Freire's (1970) emancipatory, problem-posing, critical pedagogy and the work of theatrical activist, Augusto Boal (1979).

Boal's (1979) Theatre of the Oppressed (TO) methodology was created with the purpose of providing people with an alternative language and the practical means to address and resist the various forms of oppression they experienced within their daily lives and systemically within society (Howard, 2004; Duffy, 2010; Desai, 2017). Desai's (2017) ethnographic study examined how several preservice teachers in a small, liberal arts, Catholic college in the Southern region of the United States, responded to topics of immigration in their elementary and high school classrooms. Incorporating Boal's (1979) TO, she noted that the playful nature of this practice where students can interact with each other and take on roles, allowed her to address challenging topics, such as immigration, with her class in ways that appeared less threatening while simultaneously highlighting the importance of the issues.

Boal's primary interest was his work with adults. Drawing on Boal (1979), Duffy and Vettraino's (2010) research and performative pedagogical approach acknowledged the lived realities of youth. Duffy (2010) has long incorporated performance-based learning practices with his middle school and high school students, specifically through Boal's TO method of Forum Theatre and "spect-actors," where narratives

of power and oppression are improvised multiple times by participants. His work highlighted and 
depicted the various ways in which power manifests in individual behaviour as well as social institutions, and how power imbalances affect different groups. Central to Duffy's (2010) teaching approach was the focus on power dynamics through modalities other than speech, for example, images and movement. Students were encouraged to identify instances of oppression they experienced or noticed in their world and offered opportunities to develop an action plan for their futures.

\section{Methodology}

This research study was initially part of a graduate master's research paper that was completed in 2018. The narrow sample size speaks to the time restrictions placed on the research by the graduate program and is reflective of the challenges in recruiting participants. Given the high level of experience needed from eligible participants, some respondents of the study were not included, as they did not meet the necessary requirements. The aim of this qualitative critical ethnographic research design was to examine four educators' experiences and perceptions on the ways in which racial, cultural, and social difference are predominantly conceptualized within the education system and how through performance-based approaches, these issues can be addressed.

A descriptive research design incorporated critical ethnographic methods and used a thematic analysis approach (Creswell, 2014). Grbich (2013) noted that critical ethnography is best suited for research questions that involve how group identity is constructed and represented by dominant cultural institutions such as gender, race, the economy and politics, and whose agenda this ultimately serves. Structured and tactical sampling was used in order to obtain data from experienced teachers to provide enough information to suitably address the research questions (Sandelowski, 2000). Data collection included four semi-structured interviews, of approximately 60 minutes in length, and field notes which were obtained during one-on-one interviews with the researcher and participant in order to gain firsthand insight of educators' experiences using performance-based methods in their classrooms. The use of interviews enabled unique narratives to be told, providing the possibility to uncover and address alternative types of knowledge that otherwise may not be recognized (Olson, 2011). A thematic analysis approach allowed the descriptive data to be represented in a transparent way, drawing direct connections to the research questions and providing insight into these teachers' experiences (Grbich, 2013). A blockand-file approach was used for each research question until all responses had been blocked and filed under various general themes (Grbich, 2013). Those that were similar and arose from different research questions were combined to create overarching themes (Grbich, 2013). As a result, four themes emerged from the data, all of which were directly related to the research questions surrounding teachers' experiences with integrating performance-based teaching practices in their classrooms and were supported by direct quotes from each participant. 


\section{Recruitment and Participants}

Participants in this study were experienced educators in the province of Ontario, Canada. They were either drama or dance specialists or generalists using performance-based methods in their regular teaching practices. Participant recruitment was through membership in a drama and dance education mailing list server. In order to be considered for the study, participants had to be an experienced educator for at least five years in an Ontario school board, currently teaching, and who regularly, or who had regularly in the past, practiced performance-based methods with youth between the ages eight and 18 in a classroom context. All four participants recruited were experienced teachers of over 10 years, who were currently using performance-based methods with their students in grade four to grade twelve classrooms. Research Ethics Board approval was obtained, and pseudonyms used.

Greg, a White male, was a certified high school English and drama teacher, and professional playwright employed in a diverse urban city in southwestern Ontario, where he taught for over a decade. Sasha identified herself as a Black female from the African Diaspora. She was a certified teacher, professional dancer, and dance teacher who has been teaching for over a decade. At the time, she worked for an Ontario school board, travelling to various elementary, middle school, and high schools on contract as an artist in residence. Nicole, a White female, was a certified drama and English teacher and teaching for over 15 years. She taught at a diverse high school in an urban southwestern Ontario city with students in grades nine through twelve. Kaitlin, a White female, was a certified English and drama teacher at an arts-based high school located in southwestern Ontario, teaching for over 15 years. She currently teaches English, drama, and gender studies to students in grades nine through twelve. Kaitlin has used drama and performance-based methods in her teaching for over 15 years.

\section{Findings}

Four central themes emerged out of the findings: motivating influences for including performance-based practices, practices in the classroom, perceived benefits observed, and challenges faced.

\section{Motivating Influences for the Inclusion of Performance-Based Practices}

All participants shared their personal reasons for integrating performance-based teaching practices into their classroom. Greg, Sasha, and Nicole all came from backgrounds as professional artists. Kaitlin developed an interest in performance early on in her schooling and continued this work through graduate courses.

Greg's experiences within the professional theatre community helped develop his understanding of performance and performance-based learning, making it an integral part of his everyday teaching practices with students. His approach focused on implementing a sense of structure and collectivity in the classroom, which would apply to many different subjects as it focused on skill development through repetition, practice, and collaboration. This framework of performance-based learning provided students 
with a model that allowed them to continuously practice and work towards academic and personal achievements.

Sasha's motivation to integrate performance-based practices into her teaching resulted from her own experiences growing up in an education system that lacked Black teachers and cultural representation that reflected her identity. Having been a professional dancer and dance teacher for many years, Sasha had a passion for the art of dance and performance. When she moved to Canada and began practicing forms of African dance, Sasha realized the power of both. The capacity for movement to tell stories, explore identity, build communities, and challenge traditional processes of learning was significant. Sasha noted that performative practices that encouraged self-exploration of identity and expression were particularly valuable for Black girls and young women.

Sasha: Imagine the young Black children who have never been taught about their roots or culture in the curriculum. They do not see themselves. I have a daughter coming up and I am trying to do this for her. We have to have these conversations now.

Nicole further described the significance of including performance-based practices into her classroom as a way for students to build confidence, develop critical thinking skills, and overcome personal struggles. Nicole had always worked with students varying in levels of ability and mental health, as well as diverse socioeconomic statuses and cultures. She was passionate about helping students constantly dealing with a variety of complex issues, thoughts, and emotions. She personally identified with these students, stating that, "I was one of those students myself, I have gone through my own challenges and those experiences are what has pushed me to help kids that are going through their own issues."

Kaitlin identified the importance of including performance-based practices within her daily teaching routine as a way for young people to express their identity, address struggles, or topics they felt strongly about. This also stemmed from her own personal experience with drama in the education system and the desire to express herself freely in ways that were not typically encouraged in other classes.

While there were individual situated experiences connected to performance, which influenced their teaching approach, the motivating factors shared some commonalities. They all wanted to ensure the students' well-being and address concerns. The growing levels of diversity of classrooms prompted the implementation of various performance-based practices. Additionally, they unanimously agreed that performance-based practices were highly valuable in the teaching of racial, social, and cultural difference, thus confirming that alternative pedagogical approaches are necessary to adopt in the modern Canadian educational landscape.

\section{Practices in the Classroom}

Each participant discussed how performance was incorporated into their classroom in various ways. They conceptualized and structured their particular approaches to best suit their respective learning environment and address students' needs. 
Greg integrated performance into all of his teachable subjects: Drama, English, Gender Studies, and Media Literacy. Given the high levels of identified anxiety in his classroom, the drama classes are heavily structured. His grade 12 class was in the early morning, which was challenging for many students who had jobs and disrupted home environments. In order to focus students and "collectivize the class," as he put it, he began each day with a warm-up.

Greg: I start with a physical warm-up, which is just a variation on the sun salutation. In this class there is a variety of talent and ability levels which makes it difficult to create community. When everyone is engaged in the same activity we begin to create a mutual sense of purpose. Then, we will immediately go into an improv warm-up where they go into improvisation techniques.

When implementing performance-based practices into her classroom, Sasha adapted her subject matter to reflect the group of students she was teaching. She moved around to many different learning environments, showcasing her travelling exhibits or teaching as an artist in residence. Similar to Greg, Sasha's inclusion of dance in the classroom largely focused on integrating the process of performance into her daily teaching, where discussion and reflection were valued just as much as the movement aspect of a performative piece.

Her approach focused on the connection between movement, spirituality, and culture. She further expressed that her identity as an artist was central to her work and sense of being. While technical aspects of dance were important, Sasha focused on fostering a space where students, especially marginalized students, could begin to strengthen their relationship with their mind, body, and spirit through movement and self-reflection. She offered the following example:

So, just an experience I had a couple of weeks ago. I went up North and did a retreat with a bunch of young women and we were doing a beading exercise and just talking and a lot and I told them about how one day I was introduced to African dance and just hearing the drums and how it made my body feel, this connection that I never even knew ran through my blood or my muscle memory. And the room went quiet and I told them that we were all going to try it and that it wasn't so much about the steps, it is more so the connection in the steps and why they're doing the steps and it's more so just a rite of passage in the community where dance was just as much a part of their lives like going to the doctor, or graduating, or giving birth.

Sasha believed that dance is a malleable art form that can explore a wide variety of topics and was committed to ensuring that students saw themselves represented in the subject matter.

Similar to Sasha and Greg, Nicole described the significance of the process of performance. Central to her teaching approach was the idea that critical discussion and performative exercises were not mutually exclusive, but rather, both highly valuable and necessary in the process of learning through these active practices.

Nicole: I think of it as process versus performance. I am a performance-based teacher and I use a professional theater-process-drama approach. I believe that kids should be able to explore subject matter, and acting, performing, using their voice allows them to do so. I incorporate a lot of performance-based exercises in my teaching, whether it's improv games, tableaux, or more scripted performance pieces. 
Educators' Perceptions of Performance-Based Approaches in Teaching Difference With Youth

Like other participants, Kaitlin used various performance-based practices in her classroom that focused on the process, such as a discussion surrounding a particular topic and then explored through a performative approach. She incorporated concrete drama techniques into all of her teachable subjects.

As Kaitlin described:

This year, each group of students got a different source to work from. So, one group had a photograph from a Black Lives Matter protest, then another group had a piece of text, like a poem from Audrey Lorde, and then another group had a song, and they had to use some of the different techniques that we explored in class to critically engage with them. Each group then had to write a performance piece and present their work to the class. Afterwards, we debriefed and discussed the pieces.

Using performance-based teaching approaches, such as improvisation, role-playing, scriptwriting, and Boal's (1979) TO techniques, provided students a space to freely express their thoughts, feelings, and concerns. New modes such as dance were also explored.

\section{Perceived Benefits Observed by Teachers}

All participants discussed the perceived benefits they observed through implementing performance-based practices into the classroom environment. Each one described how these methods were useful in addressing topics of power, difference, identity, and oppression. Greg described one of the main benefits of including performance-based practices into his daily teaching with his high school students is that they challenged predominant standardized models of education. Critical thinking was promoted, allowing students to explore subject matter freely.

Greg: Performance-based strategies encourage and allow students to think outside this idea of 'what is the right answer?' which is definitely important. It allows them to take control of the subject themselves. This is where we have to get to as we prepare kids for university now. How to take control of your subject matter, your learning and your understanding of it and not feeling like the answer lies outside of what you're doing.

In his classroom, Greg noticed that students responded well to performance-based methods, which included both obvious forms of performance, such as script-based drama, as well as more subtle components of the process such as repetition and open dialogue. He noticed that students were able to express themselves through these approaches, which worked to normalize different forms of cultural expression and strengthen understandings of difference in the class. He found that these methods were particularly useful with his highly diverse class, as it offered students the tools to understand and articulate their lived experiences, which, in turn, helped to address symptoms of depression and anxiety that many of them face due to a wide variety of socioeconomic and cultural factors.

Greg: My classrooms are predominantly Black, and male. What we're doing now is dealing with issues of White supremacy and issues of phallocentrism. I'm using media imagery right now with my grade 12 class so I'll go through different media imagery and we'll discuss why certain images mean what they mean in relation to narratives, in relation to masculinity, femininity, race, and mythically normative identities. 
Sasha also perceived there to be several benefits from practicing performance-based methods with her students. She noticed that using performance was highly valuable in expressing aspects of identity and addressing social and cultural differences amongst students. While many of the White students that Sasha worked with enjoyed aspects of African Canadian culture, especially dance, they lacked the contextual knowledge of that art form. Sasha attempted to address this void of cultural awareness by combining dance with a dialogue about African Canadian culture and history.

Through the integration of performance-based methods, Sasha observed a significant increase in self-confidence among her students, particularly with the young, Black female students, as well as an overall improvement in class dynamics and students' personal habits.

Nicole also discussed her perceptions of the benefits of the performance-based practices. She explained:

Performance, being present, public speaking, it is all a part of building confidence and self-esteem. It allows students to have a voice and be heard. Drama actually allows students to be in different positions, which you don't really get anywhere else. Our vocal unit in particular, is really useful in helping students build that strength and confidence.

She noticed that performance-based practices were highly beneficial to students whose first language was not English, where they were able to practice their verbal and nonverbal communication skills. This approach supported and prepared the students for different situations they may come across in their daily lives.

Lastly, Kaitlin observed many benefits of implementing performance-based practices with her students. She emphasized how the implementation of drama and performance in the classroom was useful in exploring topics of power and oppression with her students as it provided a visual example that resonated with young people. She noticed that her students developed a stronger sense of empathy, became more aware of their behaviour, and felt able to express their feelings and thoughts freely.

Through engaging in performance-based activities, Kaitlin observed her students becoming increasingly self-reflective and more critical of the world around them, specifically surrounding issues of power relations, oppression, and identity. Kaitlin offered an example of when she led a docu-drama unit with her grade 10 class where students took a specific event in history, researched it, and then created a performance piece around it. Since many of these events took place in various countries throughout the world, students portrayed different cultural identities. She noted that this activity led to a collective class discussion surrounding cultural appropriation and representation.

Although many of her students initially felt like they should be able to take on roles of characters of other races, and cultural backgrounds, they later came to the realization that this can often be inappropriate.

Kaitlin: There was one group, the group that did Japanese internment camps and they said, "I don't think we were responsible, I don't think we did enough research and we made stuff up and I don't think that was appropriate," which I thought was great. It was a really good learning experience. 
Further, this activity spoke to the influence of performance as being a deeply self-reflexive practice and valuable tool in developing one's understanding of identity, difference, and power, and communicating through conflict.

\section{Challenges Faced}

Greg described some of the challenges he experienced with implementing these strategies with his class. He felt that some of the issues commonly experienced by his students, such as high levels of anxiety and disrupted home situations, contributed to the behaviour in his class. He noted that many of them acted out and were disruptive as a way to make themselves feel more secure in their educational environment. He noted at times, his students' tendency to act out impeded his ability to engage effectively with the rest of the students during a particular activity.

Greg: There is a lot of acting out in classrooms right now because it makes students feel secure. Because everyone is reacting to the students' actions, in a sense, they are controlling everyone else.

He also felt as though there was never enough time to complete every activity. This led to a bit of tension with students who felt like they needed more time to finish a particular exercise.

Sasha expressed that one of the issues she faced with implementing dance and other new practices in the classroom was that the school board did not prioritize performance-based learning. As a result, she has had to negotiate with administrators and other teachers who challenged her methods and attempted to control her work with her students. While not noting any challenges trying to implement performance-based practices with her students, she expressed some anxiety about the future of the educational landscape.

Sasha: So many of these schools refrain from having these discussions about cultural differences and identity out of fear. Teachers often do not know what to say or how to approach a particular topic. So how do we navigate this and make kids feel safe? And the answer to this is that there are people who do this work, bring them in the school! Get the support! Prioritize it and believe in it!

Like Sasha, Nicole felt the pressure and stress of negotiating with administrators and the school board system when trying to implement alternative teaching practices within her classroom.

Nicole: The school board can really hamper progress. Policy is a big issue. The board level is more disassociated from what is actually going on within the school and these classrooms. They are not particularly supportive of my teaching methods or any form of alternative teaching in general.

She also described some of the challenges she faced as a teacher using these methods with her students. Nicole felt that it was difficult at times to use performance-based methods with her students, while still maintaining a level of control and structure within her classroom. She noted that some students were hesitant to engage in such approaches out of anxiety and fear, but suggested these challenges often opened up space for discussion, leading to important learning experiences for both herself and the class. 
Kaitlin did not notice any issues trying to incorporate performance-based practices into her classroom, but described the challenges surrounding discussions of power, difference, and oppression with her students.

Kaitlin: I think it's easy to be a teacher and avoid issues of race and diversity. You can also just pay lip service to it. If you look at the Ontario curriculum, it's very broad and it's really just a bunch of suggestions. We really have a lot of freedom to design our own content and choose materials that we want to teach and even more so at this school because we have a principal who really trusts us. Students genuinely want to talk and learn about these topics, it's on their minds.

\section{Discussion}

Educators noticed that by implementing performance-based practices in the classroom, students became more self-reflexive, empathetic, and self-confident. Through educators initiating open dialogue around topics surrounding power, oppression, and difference, the students were able to share their thoughts and feelings concerning aspects of their lived experiences and identities. The literature supports the findings on the benefits of incorporating critical, performance-based pedagogical practices in the classroom. Several studies suggested that existing power imbalances within the educational setting contribute to the ways in which students of different social, racial, and cultural backgrounds come to understand their own identities as well as the identities of others (Duffy \& Powers, 2018). By addressing difference instead of minimalizing it, students and educators are able to move towards a more equitable pedagogical framework (Daniel, 2016).

Educators felt that performative teaching methods were useful in addressing many of the issues young people currently face such as high levels of anxiety, low self-esteem, and confused sense of self. to the studies of Duffy (2010) and Gallagher (2014), the findings showed that through performance, students became more understanding of the ways in which social, cultural, and racial differences are socially constructed and systemically reinforced through Canada's institutions. Specifically, all participants described the various ways in which this approach enabled their students to express and experiment with aspects of their identity in ways that they would not otherwise have the opportunity to do or not be encouraged to do in other areas of their lives. This led them to not only be more self-reflexive of their own potential privileges and biases, but also to transform the ways in which they interacted with those whose identities were different from their own. However, due to rigid school administrations and education policies, lack of time, and disruptive classroom environments, participants found it difficult at times to implement critical performative practices with their students. Additionally, some participants experienced challenges addressing topics surrounding power, identity, difference, and oppression due to a lack of confidence to speak on a topic that they were not properly trained to teach.

Participants all used practices reflective of what the literature deems as performative critical pedagogy. The literature placed a focus on open dialogue, critical inquiry, problem-posing, and collaboration between educators and students as the basis of critical performance-based learning (Freire, 1970; 
Boal, 1979; Fels \& Beliveau, 2008; Gallagher; 2014; Desai, 2017). All educators demonstrated these components of critical pedagogy through various performative activities. Sasha's work, for instance, strongly connected to Freire's (1970) notion of praxis through dialogue and problem solving based on generative themes. This was demonstrated through her use of the theme of change as an entry point for open dialogue with her students and as a basis for performative inquiry to ensue.

Despite the benefits acknowledged by educators, this study identified various challenges associated with implementing performance-based practices in the classroom with youth (Conrad, 2004; Fels \& Belliveau, 2008; Snyder-Young, 2011). Educators addressed both the difficulty of incorporating performative methods within the classroom from a logistical perspective, as well as the struggle to utilize these methods in order to teach students about issues related to difference, identity, power, and oppression.

As various studies (Ryan, Pollock, \& Antonelli, 2009; Portelli, 2011; Snyder-Young, 2011; Solomon \& Singer, 2011; Carr \& Lund, 2014; Dei, 2014a/2014b; Daniel, 2016; Matias \& Mackey, 2016) indicated, the preparation of teachers continuously negates the importance of equitable discourses and pedagogical practices. The findings reflected this as some of the White educators faced obstacles discussing issues surrounding difference in their classrooms. This strongly connected to two of the main obstacles currently impeding the Canadian education system: the unwillingness of educators to learn and teach about White racial identity in an effective way and the disparities between a predominantly White teaching force and an increasingly diverse student population (Dei, 2007; 2014a; 2014b; Daniel, 2016).

\section{Feasibility of Implementing Performance-Based Practices}

The research suggested that the feasibility of implementing performance-based practices as a form of critical pedagogy within the classroom is largely dependent on educational policies, administrative agendas, and educators' personal inclination to use performance-based methods in order to address issues of power, difference, and oppression (Cahnmann-Taylor \& Souto-Manning, 2010; Snyder-Young, 2011; Desai, 2017). In particular, the literature consistently highlighted the issue of teacher preparation as an obstacle to the feasibility of implementing critical performative methods within the classroom (Howard, 2006; Cahnmann-Taylor \& Souto-Manning, 2010; Duffy, 2010; Snyder-Young, 2011; Schaedler, 2010; Desai, 2017). However, the findings demonstrated that it was feasible to implement performance-based practices within the classroom in instances where educators had a high level of control over their curriculum and daily routines, as well as a passion for social justice and/or performance. 


\section{Implications for Practice}

This research study illuminated several implications educators should consider when implementing performance-based practices within their classroom, where these methods are being used as a critical pedagogical tool to address issues of difference, oppression, and power. Including performance-based practices in the classroom provides students with the opportunity to address a wide variety of subject matter in a lighthearted and relaxed manner (Howard, 2004; Fels \& Belliveau, 2008; Gallagher, 2014; Desai, 2017). This further allows them to practice being in different situations and responding to various issues that they may encounter outside of the classroom.

Although not outlined in the literature, all participants found that growing mental health concerns posed a challenge to students' learning processes. They unanimously agreed that performance, although sometimes challenging to implement with students struggling with their mental health, can actually help to alleviate symptoms of anxiety by providing students with an outlet to discuss their feelings as well as topics that strongly resonate with them.

\section{References}

Boal, A. (1979). Theatre of the oppressed. Theatre Communications Group.

Cahnmann-Taylor, M., \& Souto-Manning, M. (2010). Teachers act up! Creating multicultural learning communities through theatre. Teachers College Press.

Carr, P.R., \& Lund, D. E. (Eds.). (2014). Revisiting the great white north? Reframing whiteness, privilege, and identity in education (2nd ed.). Sense Publishers.

Conrad, D. (2004). Popular theatre: Empowering pedagogy for youth. Youth Theatre Journal, 18(1), 87-106. doi:10.1080/08929092.2004.10012566

Creswell, J. W. (2014). Research design: Qualitative, quantitative, and mixed methods approaches. SAGE Publications, Inc.

Daniel, B.M. (2016). Diversity, justice, and community: The Canadian context. Canadian Scholars' Press, Inc.

Davis, T., Harrison, L. M., \& Roper, L.D. (2013). Advancing social justice: Tools, pedagogies, and strategies to transform your campus. Jossey-Bass.

Dei, G. J. S. (2007). Foreword to the first edition. In P.R. Carr \& D.E. Lund (Eds.), Revisiting the great white north? Exploring whiteness, privilege and identity in education (pp. vvii-xii). Sense Publishers.

Dei, G. J. (2014a). Personal reflections on anti-racism education for a global context. Encounters on Education, 15, 239-249. http://dx.doi.org.ezproxy.lib.ryerson.ca/10.15572/ENCO2014.13

Dei, G.S. (2014b). Foreword to the second edition. In D.E. Lund \& P.R. Carr (Eds.), Revisiting the great white north: Reframing whiteness, privilege and identity in education (2nd ed., pp. xix-xxiii). Sense Publishers. 
Educators' Perceptions of Performance-Based Approaches in Teaching Difference With Youth

Denzin, N. K. (2018). Performance autoethnography: Critical pedagogy and the politics of culture. Routledge.

Desai, S.R. (2017). Utilizing theatre of the oppressed within teacher education to create emancipatory teachers. Multicultural Perspectives, 19(4), 229-233. doi:10.1080/15210960.2017.1347875

Duffy, P. (2010). Staying alert: A conversation with Chris Vine. In P. Duffy \& E. Vettraino (Eds.), Youth and theatre of the oppressed (pp. 187-262). Palgrave Macmillan.

Duffy, P., \& Powers, B. (2018). Blind to what's in front of them: Theatre of the oppressed and teacher reflexive practice, embodying culturally relevant pedagogy with pre-service teachers. Youth Theatre Journal, 32(1), 45-59. doi:10.1080/08929092.2018.1445677

Duffy, P., \& Vettraino, E. (2010). Foreword. In P. Duffy \& E. Vettraino (Eds.), Youth and theatre of the oppressed (pp. xiii). Palgrave Macmillan.

Fels, L., \& Belliveau, G. A. (2008). Exploring curriculum: Performative inquiry, role drama, and learning. Pacific Educational Press.

Freire, P. (1970). Pedagogy of the oppressed. Continuum.

Gallagher, K. (2014). Why theatre matters: Urban youth, engagement, and a pedagogy of the real. University of Toronto Press, Scholarly Publishing Division.

Ghosh, R., \& Galczynski, M. (2014). Redefining multicultural education: Inclusion and the right to be different. Canadian Scholars' Press.

Giroux, H. (1997). Pedagogy and the politics of hope: Theory, culture, and schooling: A critical reader. Routledge.

Grbich, C. (2013). Qualitative data analysis: An introduction (2nd ed.). Sage.

hooks, b. (1994). Teaching to transgress. Routledge

hooks, b. (2003). Teaching community: Pedagogy of hope. Routledge.

Howard, L.A. (2004). Speaking theatre/doing pedagogy: Re-visiting theatre of the oppressed.

Communication Education, 53(3), 217-233. doi:10.1080/0363452042000265161

Matias, C.E., \& Mackey, J. (2016). Breakin' down whiteness in antiracist teaching: Introducing critical whiteness pedagogy. The Urban Review, 48(1), 32-50. doi:10.1007/s11256-015-0344-7

Olson, K. (2011). Essentials of qualitative interviewing. Routledge.

Portelli, J. (2011). Preface. In R.P. Solomon, J. Singer, A. Campbell, \& A. Allen (Eds.), Brave new teachers: Doing social justice work in neo-liberal times (pp. vii-xii). Canadian Scholars' Press. Inc.

Ryan, J., Pollock, K., \& Antonelli, F. (2009). Teaching diversity in Canada: Leaky pipelines, bottlenecks, and glass ceilings. Canadian Journal of Education/ Revue Canadienne De l'Éducation, 32(3), 591-617.

Sandelowski, M. (2000). Whatever happened to qualitative description? Research in Nursing \& Health, 23(4), 334-340. 
Schaedler, M.T. (2010). Boal's theater of the oppressed and how to derail real-life tragedies with imagination. New Directions for Youth Development, 2010(125), 141-151.

Snyder-Young, D. (2011). Rehearsals for revolution? Theatre of the oppressed, dominant discourses, and democratic tensions. Research in Drama Education, 16(1), 29-45.

Solomon, R.P., \& Singer, J. (2011). Introduction: Distinguishing our present context: The meaning of diversity in education for social justice. In R.P. Solomon, J. Singer, A. Campbell, \& A. Allen (Eds.), Brave new teachers: Doing social justice work in neo-liberal times (pp. 1-29). Canadian Scholars' Press. Inc.

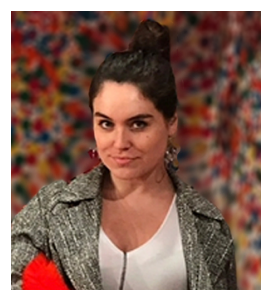

Madison E. Gaudry-Routledge works in Toronto as a social and digital media strategist at Corus Entertainment. She graduated from Ryerson University and York University's joint Communication and Culture MA program in 2018. Madison's research examines the ways in which youth learn about diversity and how this influences their understanding of the construction of identity and the oppression of marginalized groups. Her previous work at The Second City, a Toronto club known for sketch and improv comedy, led to her passion for transgressive performance as she believed such performances influenced behaviour and cultural attitudes.

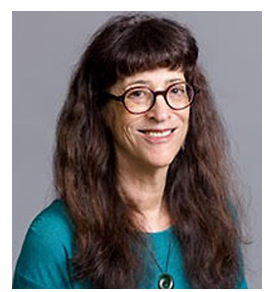

Marni J. Binder is an Associate Professor in The School of Early Childhood Studies, Faculty of Community Services at Ryerson University, in Toronto, Canada. Before coming to Ryerson in 2007, she worked in both the preservice and graduate programs at The Faculty of Education, York University. Marni also worked extensively with primary-aged children, as well as with junior-aged children as an educator in Regent Park, Toronto for 23 years. Her teaching, research, artistic practice, and publications in the arts, literacy, multimodalities, and spirituality in the lives of young children, are rooted in arts-based education research approaches and a holistic philosophy. 